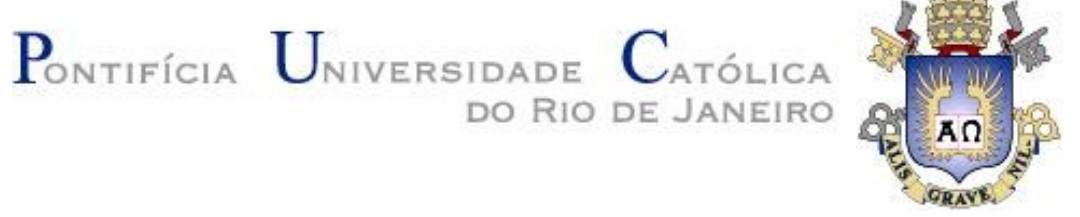

Mabel Pereira Romero

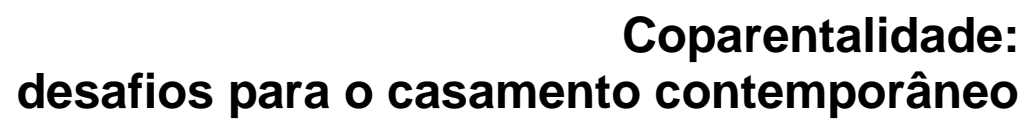

Dissertação de Mestrado

Dissertação apresentada ao Programa de Pós-Graduação em Psicologia Clínica da PUC-Rio como requisito parcial para a obtenção do título de Mestre em Psicologia Clínica.

Orientadora: Prof. Andrea Seixas Magalhães

Rio de Janeiro

Março de 2015 


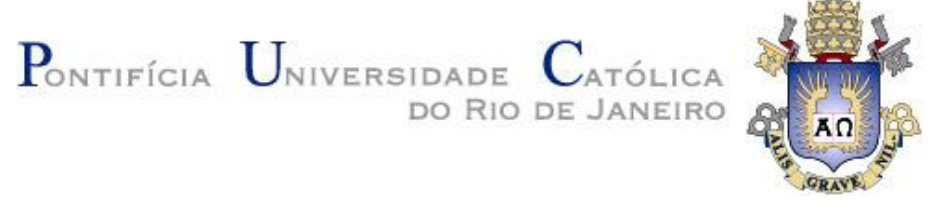

Mabel Pereira Romero

\section{Coparentalidade: desafios para o casamento contemporâneo}

Dissertação apresentada como requisito parcial para obtenção do grau de Mestre pelo Programa de Pós-Graduação em Psicologia (Psicologia Clínica) do Departamento de Psicologia do Centro de Teologia e Ciências Humanas da PUC-Rio. Aprovada pela Comissão Examinadora abaixo assinada.

Prof. Andrea Seixas Magalhães Orientadora Departamento de Psicologia - PUC-Rio

Prof. Terezinha Féres-Carneiro Departamento de Psicologia - PUC-Rio

Prof. Edna Lúcia Tinoco Ponciano Instituto de Psicologia - UERJ

Prof. Denise Berruezo Portinari Coordenadora Setorial de Pós-Graduação

e Pesquisa do Centro de Teologia e Ciências Humanas - PUC-Rio

Rio de Janeiro, 12 de março de 2015 
Todos os direitos reservados. É proibida a reprodução total ou parcial do trabalho sem autorização da universidade, da autora e do orientador.

\section{Mabel Pereira Romero}

Graduou-se em Psicologia na Universidade Federal do Rio de Janeiro em 2005. Especializou-se em Saúde Mental pelo Instituto de Psiquiatria da UFRJ em 2008. Gestalt-terapeuta formada pelo Dialógico - Núcleo de Gestalt-terapia, onde atualmente faz parte do corpo técnico e docente.

Ficha Catalográfica 


\section{Agradecimentos}

À professora Andrea Seixas Magalhães por suas orientações sempre atenciosas e delicadas e por seu interesse e confiança no meu trabalho, que possibilitaram a realização desse projeto.

Ao meu marido Matias, pela compreensão e pelo suporte nos momentos que o trabalho mais me requisitou.

Ao meu filho Antonio pelo seu amor incondicional e por, mesmo com sua pouca idade, compreender minhas ausências.

Aos meus pais, por serem meus primeiros e grandes incentivadores.

Às amigas de vida acadêmica Elisa Guahyba e Mariana Matos, pelo apoio e exemplo de dedicação e competência.

Aos entrevistados, pela disponibilidade e contribuição fundamentais para realização dessa pesquisa.

Ao CNPq, pelo incentivo financeiro desde o início desse trabalho. 


\section{Resumo}

Romero, Mabel Pereira; Magalhães, Andrea Seixas (Orientadora). Coparentalidade: desafios para o casamento contemporâneo. Rio de Janeiro, 2015. 113p. Dissertação de Mestrado - Departamento de Psicologia, Pontifícia Universidade Católica do Rio de Janeiro.

A coparentalidade pode ser compreendida como a articulação dos papéis parentais em torno dos cuidados globais e da responsabilidade conjunta pelo bemestar de uma criança. O presente estudo teve como objetivo central desenvolver uma investigação sobre como os pais que se mantém casados vivenciam a coparentalidade nos dias atuais. Especificamente, buscou-se investigar como são realizadas a transmissão conjunta de valores e princípios educativos na família, a divisão das tarefas parentais e a articulação das opiniões divergentes do casal em torno do tema. Realizou-se uma pesquisa qualitativa por meio de entrevistas semiestruturadas com quatro homens e quatro mulheres pais de pelo menos um filho entre dois e seis anos, pertencentes aos segmentos médios da população carioca. As entrevistas foram analisadas por meio do método de análise de conteúdo proposto por Bardin (2011) e do discurso dos sujeitos emergiram seis categorias de análise: um pai mais presente, divisão de tarefas e cuidados com os filhos, semelhanças e diferenças na educação dos filhos, resolução de conflitos, influências da família de origem e suporte coparental. A partir da análise do material coletado pode-se perceber que a partilha de responsabilidades e tarefas parentais entre os membros do casal é uma prática comum na atualidade. Os conflitos coparentais são percebidos como prejudiciais para a autoridade da díade parental e para o desenvolvimento saudável dos filhos sendo, portanto, evitados pelos casais. Há uma busca idealizada por uma relação coparental livre de conflitos e diferenças.

\section{Palavras-chave}

Coparentalidade; casamento; parentalidade; família; práticas educativas. 


\section{Abstract}

Romero, Mabel Pereira; Magalhães, Andrea Seixas (Advisor). Coparenting: challenges to the contemporary marriage. Rio de Janeiro, 2015. 113p. MSc. Dissertation - Departamento de Psicologia, Pontifícia Universidade Católica do Rio de Janeiro.

Coparenting can be define as the articulation of parenting roles and the sharing responsibilities about a child. The main objective of this study was to develop an investigation about the coparental relationship. A qualitative analysis was carried out through semi-structured interviews with four men and four women. They were married, parents to at least one two-year-old to six-year-old child and belonged to segments of the middle class population of Rio de Janeiro. The interviews were analyzed through the content analysis method proposed by Bardin (2011) and from the subjects' speech, six categories emerged: A more present father, Division of tasks and children's care, Resemblances and differences in raising practices, Conflict solving, Family of origin influence and coparental support. It's possible to notice the involvement of both parents on the childrearing tasks as a common practice. Coparental conflicts are seen as harmful to parent's authority and to children's development, being avoided by couples. There is an idealized search for a coparental relationship free of conflicts and differences.

\section{Keywords}

Coparenting; marriage; parenting; family; educational practices. 


\section{Sumário}

1.Introdução

2.Construção social dos valores da coparentalidade

2.1.Famílias comunitárias, hierárquicas e democráticas

2.2. Nova divisão de papéis na família 23

2.3.Transformações do papel parental

3.Entrelaçamento entre conjugalidade, parentalidade e coparentalidade

3.1. Sistema familiar, seus subsistemas e a coparentalidade 43

3.2. Coparentalidade: como, quando e onde ela acontece 50

3.3. Principais modelos de estudo da coparentalidade 60

4. Estudo de campo $\quad 67$

4.1. Participantes 67

4.2. Instrumentos e procedimentos $\quad 69$

4.3. Cuidados éticos 69

4.4. Análise e discussão dos resultados 69

4.4.1. Um pai mais presente $\quad 70$

4.4.2. Divisão de tarefas de cuidado com os filhos 74

4.4.3. Semelhanças e diferenças na educação dos filhos 80

4.4.4. Resolução de conflitos 83

4.4.5. Influências da família de origem 87

4.4.6. Suporte coparental 93

$\begin{array}{ll}\text { 5. Considerações finais } & 98\end{array}$

6. Referências Bibliográficas 105

Anexos

Anexo 1. Roteiro de entrevista 112

Anexo 2. Termo de consentimento livre e esclarecido 113 